\title{
Analgesic Efficacy of CL 48, 156 (Imidoline) in Patients with Episeotomy Pain
}

\author{
石 崎 高 志* S. S. Bloomfield** T. B. Barden***
}

Aspirin 及び Morphine の鎮痛作用は種々の臨床上 における痛みの治療に用いられて, その効果は臨床薬理 学的に疑う余地のないものとして確認されている1-5). しかしながら今日まで用いられてきた Aspirin, Morphine を含むすべての鎮痛剤に臨床薬理学上副作用を 初めとするいくつかの問題点が指摘されてきた ${ }^{3-6)}$ から 新しい鎮痛剤の開発はその必要性を有して行われてきた ように思われる。

Imidoline (CL 48156), 1-(m-chlorophenyl)-3-(2dimethylaminoethyl)-2-imidazolinone $\cdot \mathrm{HCL}$ 湔臨休 薬理学的に広範な研究上, Morphine, Methotrimeprazine 及び aspirin の鎮痛作用に類似するという特異な 薬理学的スペクトルムを有していることが確認された7). 又主として open trail による初期の人における臨床試 験はこの薬物の dose-dependent な鎮痛効果が示されて きたとされている7.しかしながら臨床薬理学上この薬 物の 2 重盲検下における適度の患者割付け並びに良くデ ザインされた鎮痛効果の検討はなされてこなかつた.

我々はこの新薬物の鎮痛効果を厳重な実験条件下で現 洔点において安全性を保証しえると考えられる経口投与 县を限定された患者数に 1 人 1 回限り投与し, 過去 5 年 間における当メデカルセンターにおいて,主としてphase II に相当する条件下における鎮痛剂に関する臨床試験の 経験に基づき8-10)この薬物の鎮痛効果を placebo と比較 検討すべく，2重盲検下にこの新薬物は鎮痛剂か否かを 副作用との，いわゆる benefit-risk relation という factor を考虑しつつ以下の実験方法に基づき研究したの

* 北海道大学医学部薬理, 前米国国際臨床薬理学フ ェロー (シンシナチ大学医学部内科臨床薬理部門)

** シンシナチ大学医学部内科臨床薬理部門助教授

*** シンシナチ大学医学部産婦人科助教授
で報告する.

\section{実験方法}

（1）患者選択

患者の選択はこれまで当メデカルセンターの過去 5 年 間において行われてきた鎮痛剤の clinical efficacy に関 する protocol に準じて行われ，次のごとくに要約され る.（a）産後48時間以内の患者で episeotomy (mediolateral 又は midline) を受け，かつ所定のコード（以後 に述べる)による“中等度 (moderate pain)”以上の 痛みを訴える者，(b) 合併者のなかつた患者，(c) 母乳 を授乳しない者，(d) Aspirin 及びその他の鎮痛剤に hypersensitivity を生じたことがない者，(e) 実験に先 立つ 6 時間以内に他の鎮痛作用を少なくとも生じうるい かなる薬物をも服用していないこと，(f) 承諾書（いわ ゆる informed written consent) にサインした者，(g) 18歳以上の者, (h) 一般状態が医学的に良好と考えられ た者, 等である.

（2）治療群の設定

4 群に分け，錠剂を各群共に 3 錠を，色，味，大き さ, その他, 識別不能の前もつて刨装 (prepackage tablets）されたものを次のごとくに設定した.

(a) Group I： 1 錠 $25 \mathrm{mg}$ Imidoline 1 錠及び 2 錠の placebo, (b) Group II : 1 錠 $25 \mathrm{mg}$ Imidoline 2 錠及 び 1 錠の placebo, (c) Group III : 1 錠25mg Imidoline 3 錠，(d) Group IV : Placebo 3 錠. な打各群とも患 者数 15 名, 総計 60 名である.

（3）各治療群に対する患者割り付けの方法

“中等度 (moderate pain 又は medium と答えた)” 以上の痛みの 3 群が前もつて設定された 4 群の治療群に 同じ痛みを訴えたものにそれぞれセットされるように制 
表 1 Treatment group stratification

\begin{tabular}{l|r|r|r|r|r}
\hline $\begin{array}{l}\text { Pretreatment } \\
\text { pain intensity } \\
\text { strata }\end{array}$ & \multicolumn{3}{|c|}{ Imidoline } & Pl- & Totals \\
\cline { 2 - 6 } & $25 \mathrm{mg}$ & $50 \mathrm{mg}$ & $75 \mathrm{mg}$ & & \\
\hline Moderate & 10 & 10 & 10 & 10 & 40 \\
Severe & 4 & 4 & 4 & 4 & 16 \\
Very severe & 1 & 1 & 1 & 1 & 4 \\
\hline $\begin{array}{l}\text { Total No. of } \\
\text { patient }\end{array}$ & 15 & 15 & 15 & 15 & 60 \\
\hline
\end{tabular}

表 2 Evaluation Method of Response to Analgesic

(1) All interviewed data recorded by one research nurse observer

(2) Subjectively evaluated pain relief and side-effect by patients themselves

(3) Pain intensity difference (PID) scores An ordinal score transposed from the question

"How much do the stitches hurt you?" is :

0 no pain

1 mild pain (" a little" or "a bit")

2 Moderate pain ("medium")

3 severe pain ("a lot")

4 very severe or unbearable pain (" a whole lot")

Hourly PID score $=($ Pretreament PI $)-$

(Hourly posttreatment PI)

(4) Two different variables measuring pain relief

(A) $\%$ patients with pain reduction greater than $50 \%$ in pretreatment pain intensity score

(B) Summed pain intensity difference (SPID) score during treatment period

り付けられた (predetermined enforced allocation). 従つて 4 人の同程度の痛みを訴える者がいずれかの組に 一回限り，2 重盲検下で割り付けられることになる. 又 この方法からこの研究は一つの between-patient comparison であることが理解される. なお crossover 法は いわゆる episeotomy pain そのものの比較的短い経過 からこの研究のためには不適当であると考えられる. 以 上の割り付け法による各群への痛みの程度による患者数 の分布は表 1 のごとくであつた.

(4) 鎮痛効果並びに副作用判定方法

今日 National analgesic study data form ${ }^{11}$ )及び同 ごく副作用判定方法 ${ }^{12)}$ とて広く用いられ，かつ当メデ
カルセンターにおいて過去 5 年間使用され8-10)て確認さ れ13)ている方法に準じて行われた. それを要約すると表 2 のごとくである. な㨬 2 に示されていない効果判定 に関するいくつかの重要な factor を要約すると一-(a) 投薬後に痛みが更に増強し何らかの鎮痛剤を必要とした ものは, その時点からインタビューを中止し, その後の 痛みの程度は最初のスコアと同じに記載した（本試験で は 3 人の患者でのみ，かかる事態が生じた). (b) もし 患者に adverse drug reation を含む何らかの emergency care を必要とする場合は code が破られその薬 物及び量を確認するか（かる事態は全くなかつた）（c） Supportive perineal care 及び時々の起立歩行に関して は投薬後の最後の 4 時間のみ許可する. (d) 薬物は空腹 時一定量の水と共に看護婦立会いの下に与え, 投与後 2 時間右腹臥位とする.（e）本試験において睡眠せる患者 は，“痛みなきは眠りうる”又は“眠りらるは痛みなし” のいずれもが正しくない14)からインタビュー時は覚醒さ れる。なお服作用に関しては leading question を用い ず，“Yes”と答えた者につき所定の方法で主観的に訴 えたもののみをチェックした.

(5) 統計学的解析法

統計学的に正当化されると考えられる方法15りより表 3 のごとくコンピュータープログラムによつて解析され た.

表 3 Statistical analysis of date

(1) Kruskal-Wallis one-way analysis of variance $(\alpha=0.05)$ for over-all comparison of effectiveness of 4 treatments with respect to

(1) mean hourly PID scores

(2) mean 6 hour summed PID scores

(2) Mann-Whitney U test $(\alpha=0.05 / 4=0.01)$ for paired comparison (drug versus placebo)

(3) Chi-square test for all other data for treatment difference (nominal data, side-effect etc.)

(4) Computer analyses by using a specially written program prechecked for accuracy

\section{結 果}

表 1 に示すごとく当実験における割り付け法に基づく 痛みの程度と患者の分布は完全であつた.これらの各治 療群における患者の平均年齢, 体重, 平均分娩回数, 6 時間以上前に服用された barbiturates 又投与された narcotics，分婏中に使用された anesthetics，分婏後本 


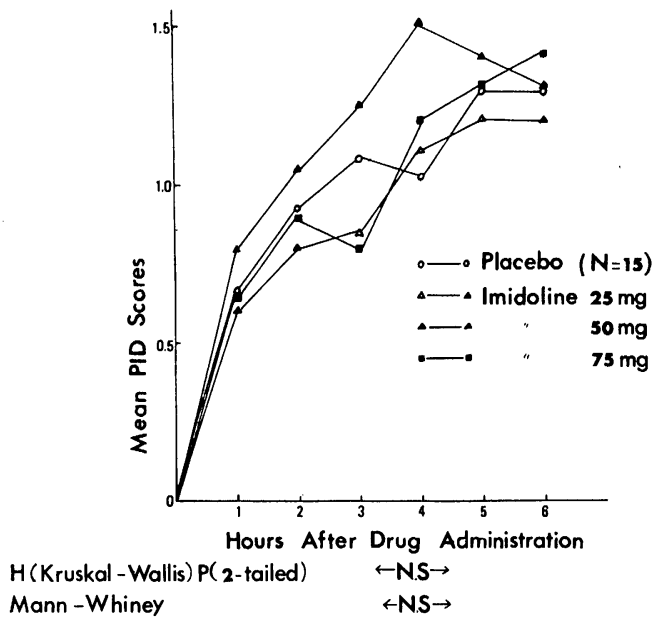

図 1 Time Effect Relationships Depicted by Hourly Mean Pain Intensity Difference (PID) Score

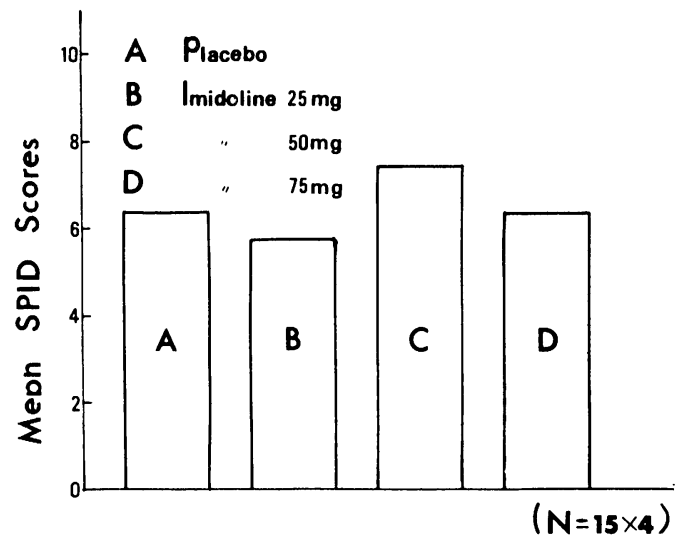

図 2 Analgesic Efficacy of Imidoline in Episeotomy Patients as Measured by 6 Hour Summed Pain Intensity Difference (SPID) Scores

奏験加入までに要した時間等の間に 有意の差はなかつ た. Pain relief に関する効果判定は図 1，2，3のご とくいくつかの判定法の下に解析されたが，薬物と plabebo との間に差は見られない. よつて research nurse observer に analgesic effecacy を識別しらるか 否かの疑問が生じた. このようなアプローチはその ob. server によつて pain score の時間経過に伴うその曲線 が異なるかも知れない可能性からも十分に予測されるか らである14). この可能性をテストするため Aspirin と その placeboをほぼ同じ患者数を同一条件下で割り付 けしその効果を分析判定した. 図 4 のごとく当 research

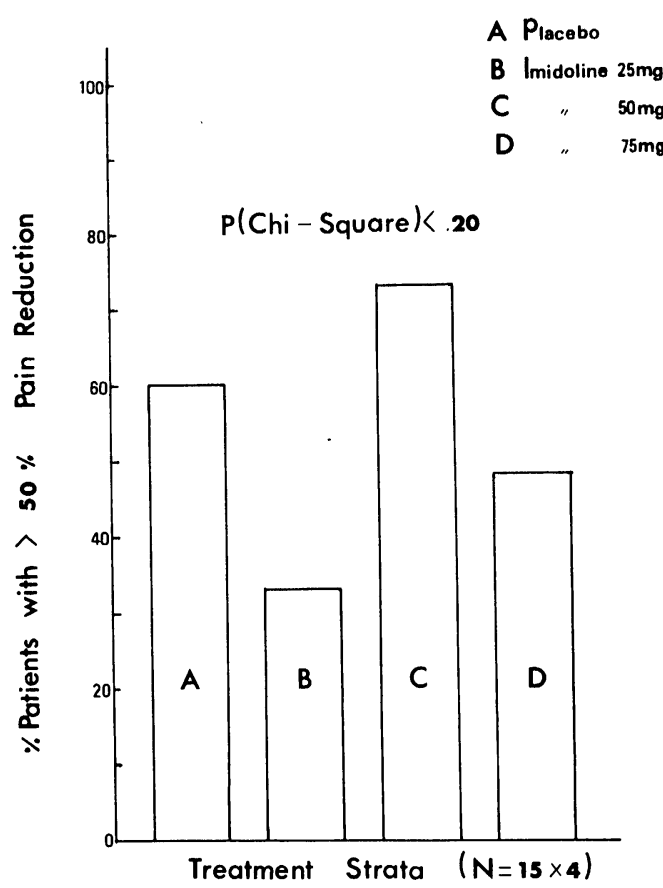

図 3 Analgesic Efficacy of Imidoline in Patients with $>50 \%$ Pain Reduction

observer は明らかに“effective drug”を placebo と 識別しうることがわかつた.

副作用のらち訴えの多かつたものは dizziness, drowsiness, headache, abdominal discomfort, weakness 等で総計38回に記载され，そのうち Imidoline $75 \mathrm{mg}$ 群が17回を占めたが，各群に訴えの種類による有意の差 はなかつた．しかしながら 1 人につき 1 回以上の副作用 を訴える頻度の上では Imidoline $75 \mathrm{mg}$ 群で有意に高 かつた(表 4). 同じく血圧に対する影響でも Imidoline $75 \mathrm{mg}$ 群で起立性低血圧を生ずる傾问が見られたが有意 の差はなく, その他体温, 呼吸数, 脈拍等の理学的所見 にも各群で有意差は見られなかつた. なお本試験中他の 鎮痛片を必要としたものが 3 名見られたが 3 群に 1 名ず つ割り付けられていた。

\section{考按並びに結語}

本試験はいわゆる薬物効果に関する Phase Iに相当 するものであると考えられる．2 重盲検下に今日までそ の効果がありとされてきた 鎮痛剂の episeotomy pain をモデルとした efficacy study は明らかに感受性の高 い再現性を有する方法として確認されている8-14). 本実 験は Imidoline が鎮痛剤なりや否やを between-patient 


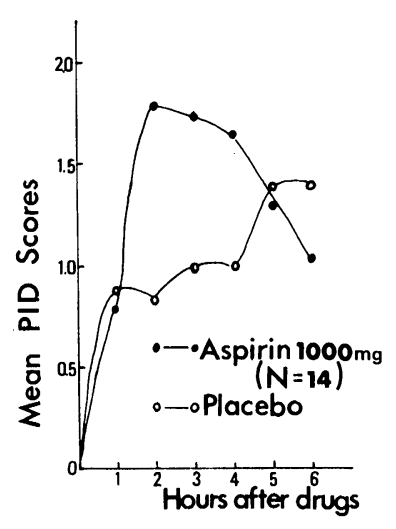

$P<N S .010505 N S$ NS

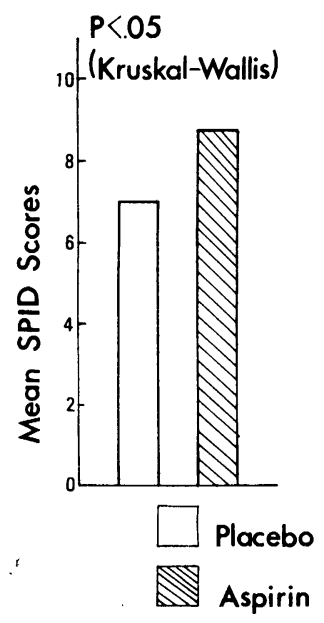

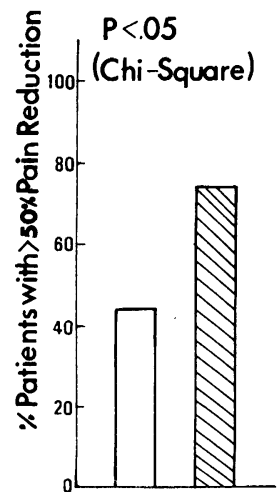

図 4 Analgesic Efficacy of Aspirin Conducted by the Same Research Nurse Oberver in Post-episeotomy Patients

表 4 Analgesic evaluation of imidoline side effects

\begin{tabular}{l|c|c}
\hline Treatment group (n) & $\begin{array}{c}\text { No. patients } \\
\text { with 1 or } \\
\text { more }\end{array}$ & $\begin{array}{c}\text { Total } \\
\text { number }\end{array}$ \\
\hline Placebo (15) & 8 & 10 \\
Imidoline 25mg (15) & 6 & 7 \\
Imidoline 50mg (15) & 4 & 4 \\
Imidoline 75mg (15) & $12^{*}$ & 17 \\
\hline Total (60) & 30 & 38 \\
\hline
\end{tabular}

* $\mathrm{p}<0.02$

comparison として比較的厳重な条件下で実施されたか ら，この実験条件下におけるこの新薬物に関する結論は 次のごとくに要約されよう.

（1） 2 重甾検下での Imidoline は placebo に比し， episeotomy pain model という再現性の高い確立され た鎮痛効果判定下では efficacy を生じなかつた。

（2）同一条件下における同一 observer による aspirin の efficacy は明らかに証明された.

(3) Imidoline 投与群のうち投与量の高い投与群で副 作用の発現頻度が高かつた.

従つて鎮痛剂としての Imidoline はその有用性を臨 床上疑つてよいものと断定される.

\section{文献}

1) Beaver, W. T. : Mild analgesics, a review of their clinical pharmacology. Am. J. Med. Sci. 250 : 577, (1965).
2) Lasagna, L.: The clinical evaluation of morphine and its substitutes as analgesics. Pharmacol. Rev. 16 : 47, (1964).

3) Beaver, W. T.: The pharmacologic basis for the choice of an analgesic. I and II. Potent analgesics and mild analgesics. Pharmacol. for Physician. 4 : No. 10 and 12, (1970).

4) Vandam, L. D.: Analgesic drugs. The potent analgetics. New. Eng. J. Med. $286: 249$, (1972).

5) Smith, M. J. H. and Smith, P. K.: The salicylates, New York, 1966, John Wiley and Sons.

6) Tainter, M. L. and Ferris, A. J. : Aspirin in modern therapy, New York, 1969, Sterling Drug Inc.

7) CL 48156 brochure for investigators, Lederli Co., Pearl River.

8) Bloomfield, S. S., Gaffney, T. E. and Howett, M. : Comperative analgesic efficacy of chlorphenesin carbamate and acetylsalicylic acid after episiotomy. Anesth. Analg. 46 : 515, (1967).

9) Bloomfield, S. S. : Torniquit and episeotomy pain as test models for aspirin-like analgesics. J. Clin. Pharmacol. 10 : 361, (1970).

10) Bloomfield, S. S., Barden, T. P. and Hille, R. : Clinical evaluation of flufenisal, a longacting analgesic. Clin. Pharmacol. Therap. $11: 747$, (1970).

11) Bellvielle, J. W., Forrest, W. H. and Brown, B. W. : Clinical and statistical methodology for cooperative clinical assays of analgesics. 
Clin. Pharmacol. Therap. $9: 290$, (1968).

12) Bellvielle, J. W., Forrest, W. H., Elashoff, J. and Laska, E.: Evaluating side effects of analgesics in a cooperative clinical study. Clin. Pharmacol. Therap. 9 : 303, (1968).

13) Houde, R. W., Wallenstein, S. L. and Rogers, A.: Clinical pharmacology of analgesics. I. A method of assaying an analgesic effect. Clin. Pharmacol. Therap. 1:163, (1960).

14) Lasagna, L.: The Clinical measurement of pain. Ann. N.Y. Acad. Sci. 86 : 28, (1960).

15) Siegel, S.: Nonparametric statistics for behavioral sciences. New York, 1956, Mc Graw-Hill Book Company, Inc.

\section{質問 関隆(杏林大薬理)}

アスピリンの効果は投与後 1 時間ないし 2 時間のとこ ろが最高になりませんか.

\section{回答}

過去の成績では 2 時間前後です. しかし会陰切開後疼 痛そのものの経過が幾つかの observer によつて異なる と思う。

\section{質問 斧田大公望(立教大)}

$50 \%$ pain-reduction という御説明がありましたがそ の規準をもら少し詳しく教えて下さい.

\section{回答}

今日確立された痛みの強さの定量方法の 1 つに Beecher, Lasagna ${ }^{14)}$ 及び Houde ${ }^{13)}$ らの方法があつた。す なわち患者の訴えを 5 段階に分けスコア化して hourly PID, summed PID, 50\% reduction of initial pain level などの反応を調べる方法です. $50 \%$ 以上の pain. reduction とは薬物投与前のスコアから投与後のスコア を差し引いて算出したものです.この值は薬がよく効い たということを示す 1 つの指標として妥当性があること が認められています。

但しこの index 1つをもつてその efficacy を論ずる ものではなく多角的にいくつかの phaseを経てその efficacy は決定されるべきであると考えられます. 